\title{
Development in Professional Cleaning Work Brings Challenges to Ergonomics
}

\author{
Anneli Pekkarinen ${ }^{*}$
}

Finnish Institute of Occupational Health, Ergonomics and Usability, Finland

\begin{abstract}
Professional cleaning is carried out worldwide in different environments and cleaning workers form an important proportion of the total working population. Cleaning is a fast-developing and fast-growing labour-intensive branch.

The aim of the present study was to evaluate the physical stress factors in cleaning work and their relationship with musculoskeletal disorders. The material was collected in three regional studies carried out in northern Finland during a ten-year period. Special attention was paid to the changes in professional cleaning.

The results showed that cleaning is moderately heavy work containing continuous moving and repetitive movement of the upper extremities mainly when mopping. The cleaners themselves estimated that these two stress factors caused the greatest physical stress in their work. In the ten-year period the statistical test showed no significant reduction in the amount of repetitive movements. Instead, the working postures had improved. Bent, twisted and awkward working postures, and working with hands over shoulder level, had decreased significantly $(\mathrm{p}<0.001)$. The cleaners also reported that there had been significant reduction in manual lifting and carrying during the years $(\mathrm{p}<0.05)$. No statistical difference was found in the stress caused by heavy physical work. The results also revealed that musculoskeletal disorders are common among professional cleaners. Particularly, pain in the neck and shoulder area clearly increased with age.

Cleaning is done mostly with the hands and the body, and cleaners are able to plan their own work to some extent. This enables them to influence the physical workload and musculoskeletal disorders. Cleaning techniques, tools, and machines have recently undergone major improvements, which has resulted in training needs for cleaners. Good results were achieved in adopting ergonomic ways of working after a training intervention. The conclusion is that professional cleaners would greatly benefit from relevant training in ergonomics and working techniques.
\end{abstract}

Keywords: Cleaning, repetitive movements, musculoskeletal disorders, intervention, training.

\section{INTRODUCTION}

Professional cleaning work is a fast-developing and fastgrowing labour-intensive branch. It is carried out worldwide in different environments. Cleaning workers form an important proportion of the total working population. For instance, $3 \%$ of the population in the USA, $4 \%$ in Finland, and $10 \%$ of the female working population in Spain are cleaners [1]. Professional cleaning is one of the most common occupations in the European Union. The estimated number of full and part time cleaners in the EU is three million [2-4]. In Finland, about 70,000 professional cleaners are employed by enterprises in the private and public sector $[5]$.

In many countries, cleaning work is predominantly done by women, with a relatively high proportion of ageing women. Immigrants constitute another major group doing cleaning work in many industrialised areas [1]. In Finland, over $90 \%$ of professional cleaners are women and about $10 \%$ are immigrants. The number of multinational workers is constantly growing [5].

*Address correspondence to this author at the Finnish Institute of Occupational Health, Ergonomics and Usability, Finland;

E-mail: Anneli.Pekkarinen@ttl.fi
Cleaners have unfavourable working hours, since they often work before or after the regular working hours. Moreover, part-time employment is common, and although cleaning is sometimes done in groups or teams, cleaners often work alone. In addition, cleaners' occupational and educational status may be low. These features can be seen to signify precarious employment [1-5].

In this situation, the main challenges lie in increasing the attractiveness of the work, providing vocational education, and attending to the health and work ability of cleaners [1, $5]$.

The main goal of cleaning is to maintain appropriate hygienic conditions in buildings. This is done by cleaning the surfaces, particularly floors, as well as furniture, sanitary fittings, windows etc. Cleaning consists of different tasks, such as mopping, sweeping, swabbing, dusting, vacuuming and buffing $[1,2]$. Cleaning work has an important role in public and work environments as it enhances health and well-being [2].

Over the past years, major technical advances have been made in the design of cleaning equipment and machines. Single-disk floor cleaning machines [6], buffing machines, mopping systems and vacuum machines [7] have been evaluated and studied from the ergonomic point of view. Modifications have been recommended for the design of 
these machines. According to Swedish studies [8, 9], redesigning of toilet brushes and mops (a bent shaft) was shown to reduce loading and awkward postures. Different mopping techniques in floor cleaning have been compared in Sweden [10], Finland [11, 12] and Denmark [13]. The "push" method was found to be less loading than the "number of eight" method, and damp/dry mopping less loading than wet mopping.

Even though cleaning methods, equipment and machines have improved, researchers, designers and manufacturers should still strive for ensuring good health and work ability for cleaners [7].

Musculoskeletal disorders are common among cleaners. In Sweden, $51 \%$ of 9,000 hotel and office cleaners informed pain and discomfort in the shoulders and hands and $46 \%$ in the extremities on a weekly basis [14]. In questionnaire surveys, $74 \%$ of the cleaners in the UK reported experiencing muscular aches, pain and discomfort in the last year. The main body areas of concern were the low back (46\%), neck (33\%), knees (24\%), right shoulder (23\%) and right wrist/hand (22\%) [15]. The one-month prevalence of severe bodily pain was $47 \%$ in general, $43 \%$ for neck, $59 \%$ for upper back, and $63 \%$ for lower back among 941 hotel room cleaners in Las Vegas, USA [16].

The aim of the present study was to evaluate the physical stress factors in professional cleaning work and their relationship with musculoskeletal disorders. Special attention was paid to the changes that occurred during the ten-year period. Ways to improve the level of ergonomics through regional training interventions were also explored.

\section{MATERIALS AND METHODOLOGY}

This is an experimental research with a longitudinal design. The material was collected in three regional studies carried out in northern Finland during a ten-year period. The ergonomic model used in these studies is shown in Fig. (1).

\subsection{Materials}

The first study (I) was carried out in the Kemi-Tornio Region in 1997, with a follow-up questionnaire implemented in 1999. Four employers were chosen as the targets of this study: one large and one small employer from both the public and the private sector. The study group consisted of 203 professional cleaners working in a hospital, a school, an office, a hotel, and a supermarket [17-19].

Five employers with 169 professional cleaners were involved in the second regional study (II) carried out in Rovaniemi in 2001. The nature of the cleaning sites varied greatly; they included a health care centre, a factory, a hotel, offices, and trains.

The third study (III) was started in Oulu in 2006 and completed at the end of 2008. Two large enterprises offering cleaning, maintenance, and additional services each selected as their object a single large piece of real estate for which they arranged the whole maintenance. The selected premises were a supermarket and a medical supplies centre. In the supermarket, the enterprise took care of the bottle room, and in the medical supplies centre the medical devices were washed by the cleaners.

\subsection{Methodology}

The study process was similar in all three studies. Each study began with a questionnaire charting the cleaners' work and occupational competence, health and disorders, physical stress factors, cleaning equipment and machines. The number of responses for the first, second, and third study were 121,115 and 79, respectively. The Chi-Square test was carried out to compare with each other the cleaners' estimations about the physical stress factors expressed in these three questionnaires.

Next, the ergonomic surveys were carried out in different kind of cleaning sites. Cleaners were observed and videoed in their daily work, their heart rate was measured, and

\section{Physical stress factors - Heavy physical work \\ - Manual lifting and carrying \\ - Work postures \\ - Repetitive movements}

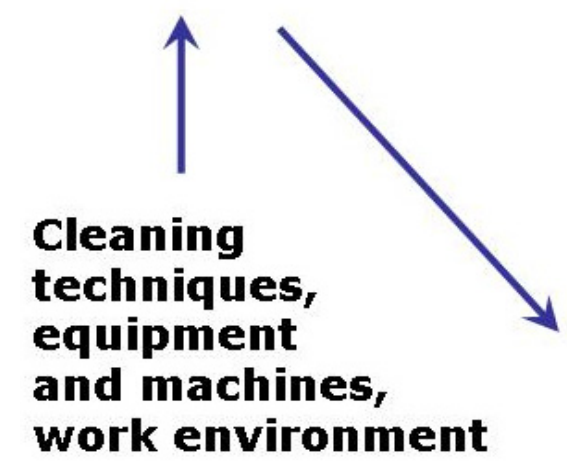

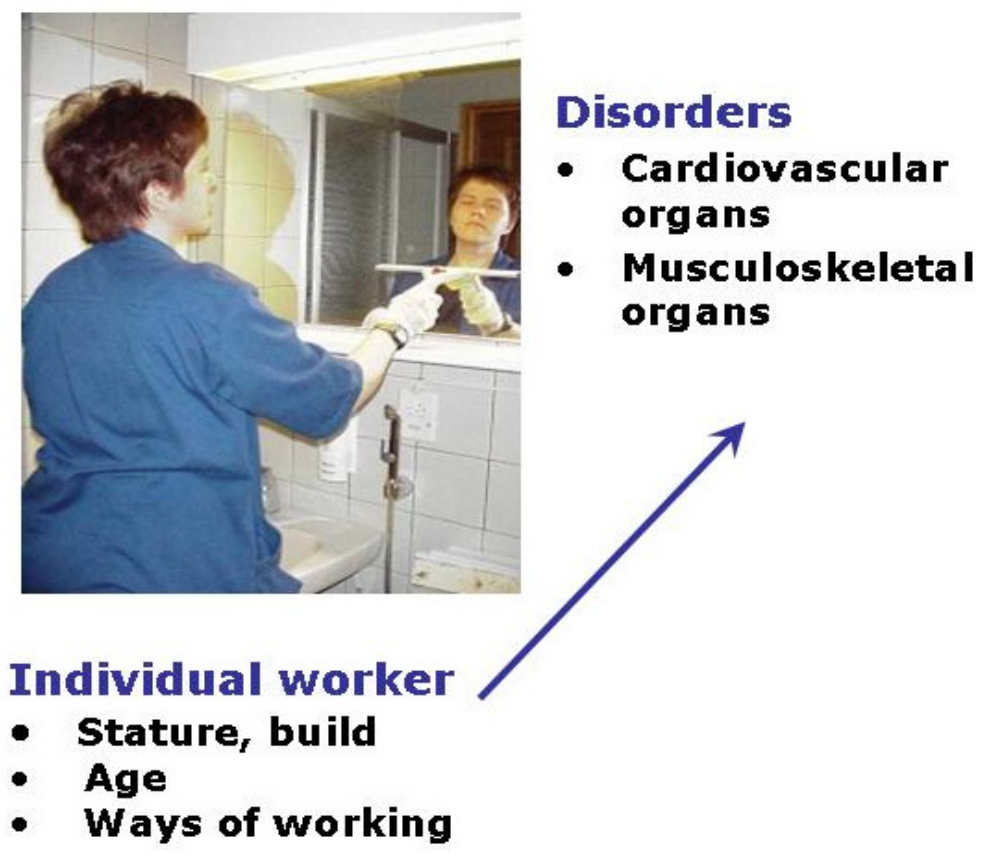

Fig. (1). Ergonomic model used in the study. 
physical stress assessed using the ergonomic workplace analysis [20]. The number of test persons varied from five to eight in different studies. The observations concentrated on work postures and repetitive movements, and manual lifting and carrying. The ergonomic quality of cleaning equipment and machines, as well as their use in practice in each cleaning site, was assessed by the researcher.

\subsection{Training interventions}

In the first study (I), the training intervention consisted of two two-day courses including lectures, discussions and group work. The best working habits were listed together with the cleaners during the courses. The following suggestions were made:

- $\quad$ Adjust the bars and handles to suit yourself

- $\quad$ Squat instead of bending your back

- Don't stretch, go closer to the object

- Use your hand or thigh for support, or sit down if possible

- Use both hands in turn

- Wipe from the top downwards

- Don't press unnecessarily hard
- $\quad$ Go forwards when possible

- Consider how much water is needed in the cleaning.

In the second study (II), the intervention contained six half-day lessons on ergonomics and other health and safety issues. In addition, a slide show "Ergonomics in Professional Cleaning" was prepared and published on the Internet during the project [21]. The slides illustrated different working tasks with three photos: bad, better and the best way of working. Vacuum-cleaning is shown as an example of the slides in Fig. (2).

The third study (III) concentrated on interaction between cleaning and other maintenance work of premises and facilities. The intervention consisted of five guided team meetings and the tasks between them. Ergonomics was discussed in these meetings among other things [22].

The material collected in the questionnaires and ergonomic surveys was used in all of the training interventions. For instance, a good and bad mopping technique was illustrated by the photos and videos taken in the cleaner' own work sites.

\subsection{Follow-Up Questionnaire}

In the first study (I), the effects of the intervention were investigated later by a follow-up questionnaire. It was sent to
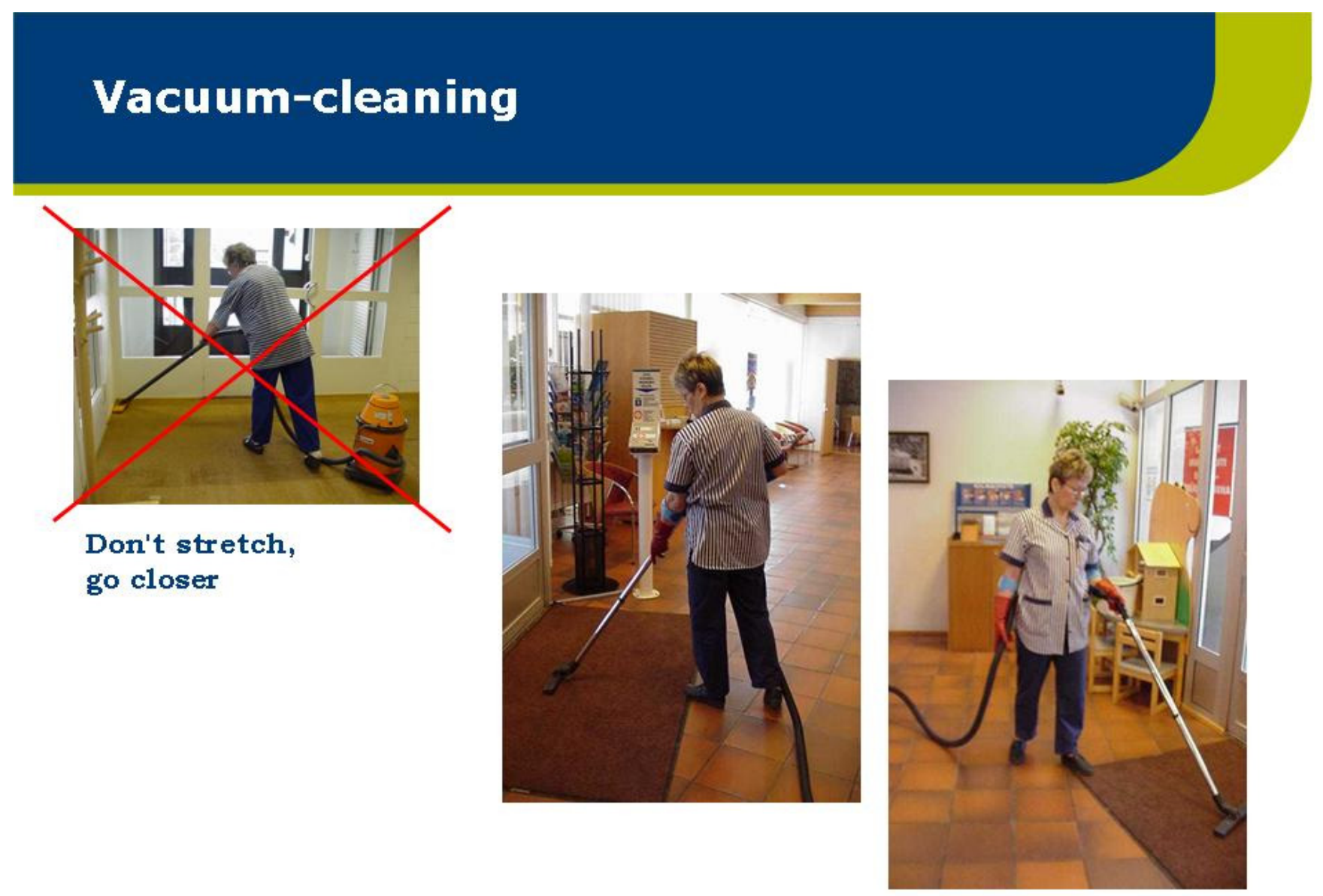

Fig. (2). Example slide of the slide show prepared during study II. 
47 cleaners, who had attended the training course and were still employed by the same employer. 30 responses (64\%) were received $[18,19]$.

\section{RESULTS}

\subsection{Questionnaire Surveys}

According to the questionnaires, the order of musculoskeletal problems caused by cleaning work was the same in all three studies. Most often, the problems appeared in the neck and shoulder area, then in the back and, third, in the arms.

Frequent or some pain during the last year was complained in the neck and shoulder area by $30-55 \%$, in the back by $15-40 \%$, and in the arms by $10-35 \%$ of the respondents. The number of complaints was lowest in the newest study (III), but then, the respondents also were the youngest.

Particularly, pain in the neck and shoulder area clearly increased with age. In the third study (III), the mean age of respondents was 30 years, and 30\% complained of frequent or some pain in the neck and shoulder area. In the first study (I), the mean age of respondents, all of whom were employed in the private sector, was about 40 years, and of them $47 \%$ reported frequent or some pain in the neck and shoulder area. In a group of 50-year-old cleaners working in the public sector, the proportion of these complaints was $61 \%$.

The cleaners themselves estimated that the repetitive work movements and continuous moving caused the greatest physical stress in their work (Fig. 3). A lot of moving continuously from place to place was reported by $83 \%$ of the respondents in $1997,66 \%$ in 2001 , and $75 \%$ in $2006-8$. Monotonous repetitive work movements caused a lot of stress for $70 \%$ in $1997,73 \%$ in 2001 , and $67 \%$ in $2006-8$. In these two stress factors, no statistically significant reduction had occurred in the ten-year period.

Instead, the working postures had improved. The stress caused by bent, twisted and awkward working postures was reported by $50 \%$ of the respondents in $1997,43 \%$ in 2001 , and $20 \%$ in 2006-8. The reduction was statistically significant $(p<0.001)$. Working with hands over shoulder level had decreased significantly $(\mathrm{p}<0.001)$ : from $27-26 \%$ in 1997 and 2001 to only $3 \%$ in 2006-8.

The cleaners also reported that there had been significant reduction $(\mathrm{p}<0.05)$ in manual lifting and carrying during the years. The percentage was $37 \%$ in $1997,41 \%$ in 2001 , and $23 \%$ in 2006-8. There was also reduction in the stress caused by heavy physical work ( $26 \%$ in $1997,25 \%$ in $2001,14 \%$ in 2006-8), but the difference was not significant.

In all three studies, the cleaners estimated the quality of cleaning equipment and machines as fairly good. The equipment that was regarded to require most development was the same in 1997 and 2006: the vacuum cleaner, window and toilet cleaning equipment, and the cleaning trolley.

\subsection{Ergonomic Surveys}

Based on the heart rate measurements, cleaning work was assessed as moderately heavy (mean heart rate 100-125

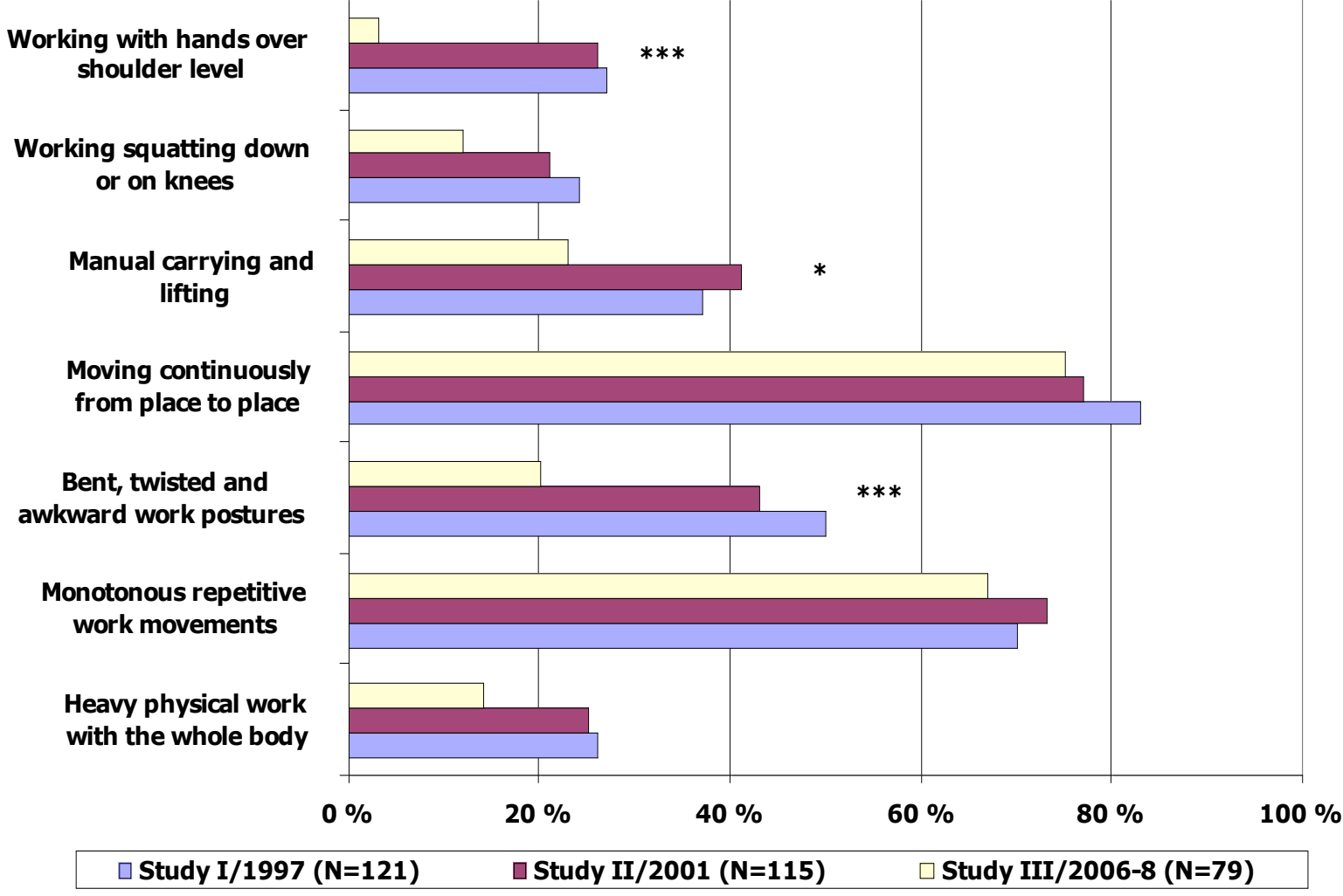

Fig. (3). Physical stress factors in cleaners' work according to the questionnaires. The percentage of a lot answers. $\left(* \chi^{2}\right.$-test $\mathrm{p}<0.05$, *** $\chi^{2}$ test $\mathrm{p}<0.001$ ). 
beats/min) but containing heavy work phases such as moving and lifting garbage bags or cleaning warm saunas. Use of water was associated with the physical stress, and the observations showed that dry and damp cleaning methods had gained ground in recent years.

The mopping of floors was the most common working task, and it involved repetitive movement of the upper extremities. Mopping technique was generally good. Stress in the neck and shoulder area sometimes appeared, if the handle of the mop was too long. Bent postures of the back were common when wiping objects that were situated low or when using a vacuum cleaner. Hands were above shoulder level when wiping windows or white boards, for instance.

The cleaning equipment and machines were estimated by the researcher, and they fulfilled the basic ergonomic requirements. In the ten-year period, the essential improvements in hand tools were easier adjustability, reachable handles and all-round joints. The micro-fibre cloths had made cleaning easier and decreased the use of water. In addition, machines had been acquired for the cleaning of wide floor surfaces.

However, the spaces to be cleaned were often impractically furnished, and cleaning had not been taken into account in the planning of the surfaces, rooms and buildings. This observation was made in all three studies.

\subsection{Interventions}

In the follow-up questionnaire completed after the training courses (study I), the cleaners reported that the subjective physical burden had been reduced. The possibilities to plan their own work (e.g. content, order, and pace of work) had increased. They had received more and better equipment and machines to their cleaning sites, and had learned better cleaning methods. Fig. (4) illustrates the percentage of cleaners who had adopted the recommended ways of working. $87 \%$ of them adjusted the bars and handles of the equipment after the training. Most of them employed dynamic movements instead of static, and used both hands in the cleaning work. In 1999, quite few cleaners (23\%) had switched to waterless methods in their cleaning sites.

The slide show about ergonomics in professional cleaning, prepared after the second study (II), has been widely used, especially in vocational institutions. In 2007 , the project's website had still had over 2,000 visitors.

The results of the third study (III) showed that teamwork brings well-being to both cleaners and maintenance workers in the field of real estate maintenance. Since the maintenance workers are mostly men, they can help the female cleaners with the heaviest work tasks, such as carrying and lifting garbage bags or opening stacked windows. They agreed about this kind of assistance in team meetings.

\section{DISCUSSION}

This research summarises the results of three regional studies on professional cleaning work. Eleven employers both from the public and the private sector participated in the studies and about 450 professional cleaners were involved. The nature of their cleaning sites greatly varied from offices to factories and trains. The physical stress factors and prevalence of musculoskeletal disorders were investigated using similar methods, a questionnaire and ergonomic
Using waterless methods

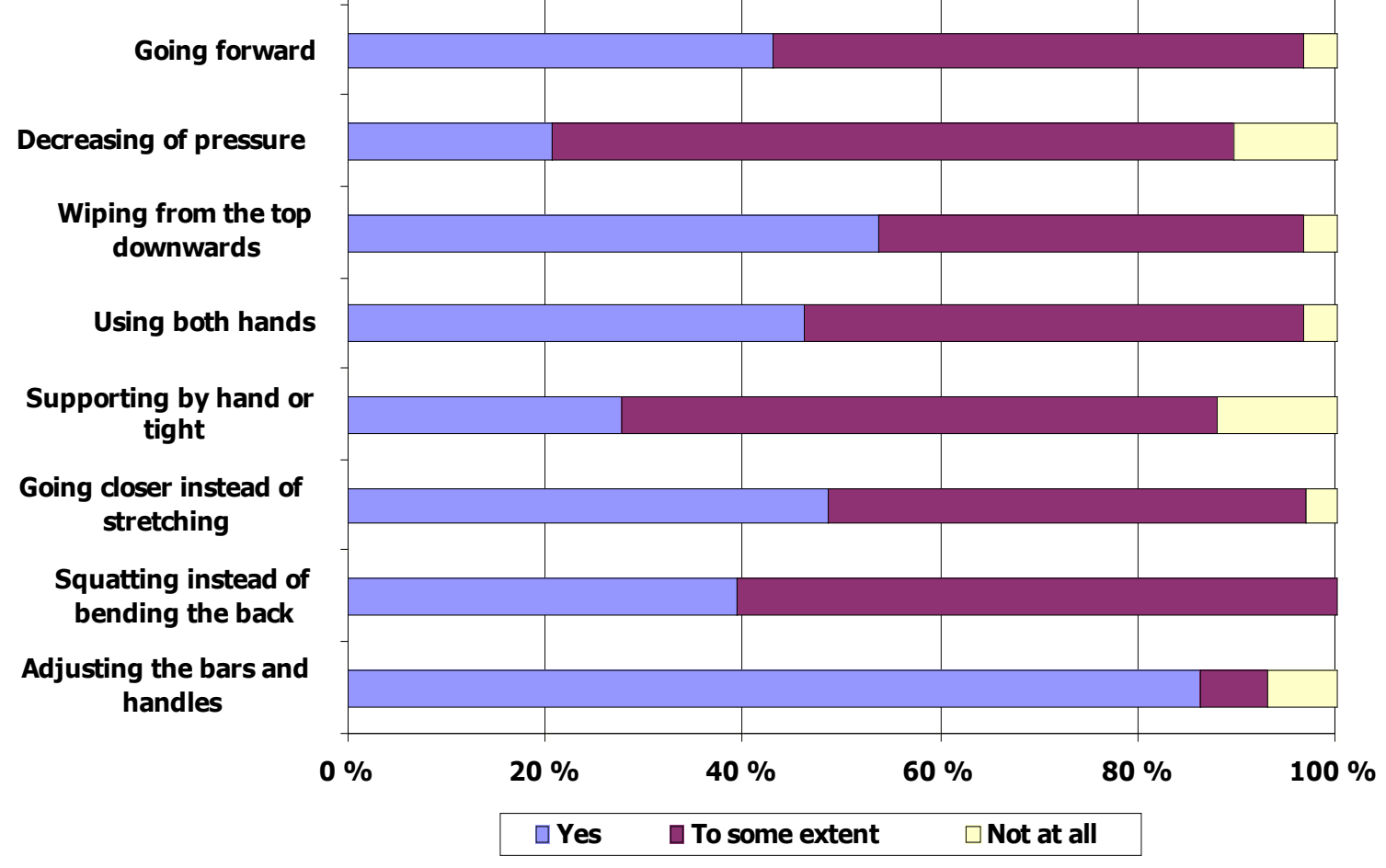

Fig. (4). Adopting ergonomic ways of working. Results of the follow-up questionnaire in study I, N=30. 
surveys. Special attention was paid to changes that had occurred in the ten years that had passed between the first and the last study. Ways to improve the level of ergonomics through training interventions were also explored.

\subsection{Physical Stress Factors and their Reduction}

As in previous studies [11, 12], the professional cleaning work was assessed to be moderately heavy work but to contain heavy work phases. Use of water in cleaning has decreased in recent years. Dry and damp mopping has been shown to be less loading than wet mopping $[12,13]$ and they are more popular in Finland than in other countries. Comparison of the questionnaire results showed that the cleaners themselves reported about significant reduction in the stress caused by manual lifting and carrying, but not in heavy physical work.

The repetitive movements of upper extremities are typical to cleaning work and they may lead to musculoskeletal disorders, as found in several studies [2-4, 11-13]. In the ergonomic surveys, the repetitive movements of concern were observed in mopping, wiping and vacuum cleaning at the different cleaning sites. The cleaners also estimated the repetitive work movements stressful in their work with no statistically significant change in the ten-year period according to the questionnaires.

As shown earlier, awkward working postures, like bent postures of the back and working with hands over shoulder level or by squatting down, cannot be totally avoided in cleaning work $[2-4,7,9]$. According to the ergonomic surveys and questionnaires of this research, however, the working postures have significantly improved in recent years.

Attention should be paid to the development of cleaning equipment, since about $80 \%$ of cleaning work is manual and performed by using non-powered tools, and about $30 \%$ of that consists of mopping [5, 13]. Even though cleaning techniques, tools, and machines have recently undergone improvements, researchers, designers and manufacturers should still strive for reducing the physical stress of cleaners. Cleaning managers, trainers and purchasers should be aware of the ergonomic guidelines for equipment selection in order to ensure safe use of the equipment at the cleaning sites [7].

\subsection{Prevalence of Musculoskeletal Disorders}

Prevalence of musculoskeletal pain reported in this research was either similar or lower than prevalence data in previous studies on cleaners [14-16]. The comparison is difficult, since the appearance of pain has been inquired on yearly, monthly or weekly basis in different studies.

The main areas of concern in the body also differ. In Sweden [14], as in Finland, the cleaners most often complained pain in the shoulders, while back pain was most frequent in the other countries $[15,16]$.

Similarly to previous research [14-16], this study also indicated that cleaners suffer from musculoskeletal health problems and a comprehensive approach to reduce these health inequalities is essential.

\subsection{Intervention Effects}

Interventions or training in ergonomics were suggested in almost all studies on cleaners $[1-7-9,12,13,15,16]$ in order to develop working techniques and reduce musculoskeletal disorders.

This was confirmed in this research. The follow-up questionnaire (study I) showed that after the training courses, the cleaners had adopted ergonomic ways of working and were more active in asking for better working tools and machines. There is also an urgent need for updated training material about ergonomics in cleaning, since over five years old material was still widely used.

\subsection{Study Limitations}

In this research, the physical stress factors and the prevalence of musculoskeletal disorders in professional cleaning work were investigated using similar methods in three separate studies carried out in 1997, 2001 and 2007. In the questionnaires, the number of respondents was quite small (from 79 to 121) and their mean age varied greatly (from 30 to 50 years). Since the disorders were much more connected to age of the respondents than to the year of the study, it was not possible to analyse the change in the prevalence of musculoskeletal disorders.

The assessment of physical stress factors was based both on the ergonomic surveys in different cleaning sites and on the opinions of the cleaners in the questionnaires. The results concerning the development of cleaning techniques, tools and machines were quite similar, even though the cleaning sites varied from offices to factory and train wagons. Based on this material, we could not find out if the advantage got from better cleaning tools and methods is used to widen the areas to be cleaned or to reduce the physical stress of the cleaners.

\section{CONCLUSION}

In the ten-year period reviewed in this research, many changes have taken place in cleaning work. Cleaning techniques, tools, and machines have undergone major improvements. Perhaps because we all clean to some extent, the erroneous impression persists that everyone can clean. However, professional cleaning work requires wide knowledge and skills. The question is if the theory and practice go together. For instance, musculoskeletal disorders are still common in cleaning work and clearly increase with age.

Cleaning is done mostly with the upper extremities and the body, and cleaners are able to plan their own work to some extent. This enables them to influence their physical workload and musculoskeletal disorders. The conclusion is that professional cleaners would greatly benefit from relevant training in ergonomics and working techniques arranged at vocational schools and workplaces.

\section{REFERENCES}

[1] Zock JP. Word at work: cleaners. Occup Environ Med 2005; 62: $581-4$.

[2] Kumar R, Kumar S. Musculoskeletal risk factors in cleaning occupation - A literature review. Int J Ind Ergon 2008; 38: 158-70.

[3] Louhevaara V. Cleaning in the European Union. Finnish Institute of Occupational Health. Electronic Journals: Työterveiset Journal: Special issue 1999-2. [2009 August 28] Available from http://www.ttl.fi/Internet/English/Information/Electronic+journals/ Tyoterveiset+journal/1999-02+Special+Issue/06.htm

[4] Krüger D, Louhevaara V, Nielsen J, Schneider T. Risk assessment and preventive strategies in cleaning work. Hamburg: 
Wirtschaftsverlag NW; Werksstattberichte Wissenschaft + Technik Wb 13, 1997.

[5] Kantowitz BH, Roediger H, Elmes D. Experimental psychology 9th ed. Belmont, CA: Wadsworth 2009; p. 8-15.

[6] Haslam RA, Williams HJ. Ergonomics conciderations in the design and use of single disc floor cleaning machines. Appl Ergon 1999; 30: 391-9.

[7] Woods V, Bucle P. An investigation into the design and use of workplace cleaning equipment. Int J Ind Ergon 2005; 35: 247-66.

[8] Hoffmann ER. Naïve judgments of stimulus-response compatibility. Forthcoming 2009 Available from: erroldot@net connect.com.au.

[9] Bussmakers MP, de Haan A. When it sounds like a duck and looks like a dog. Auditory icons vs. earcons in multimedia environments In: Proceedings of International Conference on Auditory Displays; 2000; Atlanta: ICAD 2000; pp. 184-9.

[10] Hagner IM, Hagberg M. Evaluation of two floor-mopping work methods by measurement of load. Ergonomics 1989; 32: 401-8.

[11] Søgaard K, Laursen B, Jensen BR, Sjøgaard G. Dynamic loads on the upper extremities during two different floor cleaning methods. Clin Biomech 2001; 16: 866-79.

[12] Louhevaara V, Hopsu L, Søgaard K. Cardiorespiratory strain during floor mopping with different methods. Proceedings of the xivth triennial congress of the international Ergonomics association and $44^{\text {th }}$ annual meeting of the human factors and ergonomics society. San Diego, CA, USA. 2000; pp. 518-20.

[13] Hopsu L, Toivonen R, Louhevaara V, Søgaard K. Muscular strain during floor mopping with different cleaning methods. Proceedings of the XIVth Triennial Congress of the International Ergonomics Association and 44th Annual Meeting of the Human Factors and Ergonomics Society. San Diego, CA, USA. 2000; pp. 521-4.
[14] No author listed. Statistiska centralbyrån, Arbetsmiljöverket. Arbetsmiljön 2005 (Sveriges officiella statistik, statistiska meddelanden AM 68 SM 0601). Solna, Sweden, 2006.

[15] Woods V, Buckle P. Musculoskeletal health amongst cleaners and recommendations for work organisational change. Int J Ind Ergon 2006; 36: 61-72.

[16] Krause N, Scherzer T, Rugulies R. Physical workload, work intensification, and prevalence of pain in low wage workers: Results from a participatory research project with hotel room cleaners in Las Vegas. Am J Ind Med 2005; 48: 326-37.

[17] Pekkarinen A, Anttonen H. Work ability of professional cleaners regional intervention. In: Scott PA, Bridger RS, Charteris J, Eds. Global ergonomics. Proceedings of the Ergonomics Conference; September 9-11 1998; Cape Town. Amsterdam: Elsevier 1998; pp. 251-4.

[18] Pekkarinen A. Työkykyyn panostus kannatti Kemi-Torniossa Siivoussektori 2001; (7):32-3.

[19] Pekkarinen A, Anttonen H. Siivousalan alueellisen interventiohankkeen vaikuttavuuden arviointi. Tampere: Ministry of Social and Health Affairs; Työsuojelujulkaisuja 38. Sweden 2000.

[20] Ahonen M, Launis M, Kuorinka T. Ergonomic workplace analysis. Helsinki: Finnish Institute of Occupational Health 1989.

[21] Pekkarinen A, Ojala S. Ylläpitosiivouksen ergonomia. PowerPoint Presentation. Finnish Institute of Occupational Health. [2009 August 28] Available from http://www.ttl.fi/NR/rdonlyres/ 69BE9 67B-9B98-4C32-9648-C1FD31536661/0/siivous_ttl.pdf

[22] Pekkarinen A, Hannonen H, Mäkitalo J, et al. Teamwork brings well-being to premises and facilities maintenance work. Abstracts of International Symposium ACTIVITY 2008. Helsinki, Finland, 2008; p. 66.

(C) Anneli Pekkarinen; Licensee Bentham Open .

This is an open access article licensed under the terms of the Creative Commons Attribution Non-Commercial License (http: //creativecommons.org/licenses/ by-nc/3.0/) which permits unrestricted, non-commercial use, distribution and reproduction in any medium, provided the work is properly cited. 